Bundesgesundheitsbl 2009 · 52:1069-1082 DOI 10.1007/s00103-009-0951-0

Online publiziert: 18. Oktober 2009

(c) Springer-Verlag 2009
S.H.E. Kaufmann ${ }^{1}$ - A.L. Meinke ${ }^{2}$ A. von Gabain ${ }^{2}$

${ }^{1}$ Max-Planck-Institut für Infektionsbiologie, Berlin

${ }^{2}$ Intercell AG, Wien

\title{
Neue Impfstoffkonzepte auf Basis moderner Erkenntnisse der Immunologie
}

Impfungen zählen zu den kosteneffizientesten Maßnahmen der Medizin. Jährlich werden mehr als fünf Millionen Menschenleben durch Impfungen gerettet. Die Impfung wird zwar häufig als erfolgreichstes Produkt der modernen immunologischen und mikrobiologischen Forschung bezeichnet. Ein Blick zurück zeigt aber, dass diese Aussage nicht ganz zutreffend ist. Geimpft wurde schon zu Zeiten, als die Menschen noch keine Kenntnisse über die Immunologie und Mikrobiologie besaßen. So führte Lady Montague Anfang des 18. Jahrhunderts in England die Variolation ein. Dabei handelte es sich um die Verabreichung menschlichen Pockenmaterials unter die Haut. Dies war ein gefährliches Unterfangen, das Edward Jenner Ende des 18. Jahrhunderts durch die Einführung der Impfung mit Kuhpocken deutlich sicherer machte. Auch Jenner verstand die zugrunde liegenden Mechanismen nicht. Dennoch war ihm der Durchbruch gelungen: Die Jennersche Pockenimpfung setzte sich durch und führte zum bislang größten Erfolg der Impfgeschichte, als die Weltgesundheitsbehörde (WHO) am 8. Mai 1980 die Eradikation der Pocken offiziell erklärte. Das Geheimnis der Kuhpockenimpfung liegt darin, dass diese Erreger für den Menschen nur eine geringe Pathogenität besitzen, mit den humanen Pockenviren aber immunologisch nahe verwandt sind. Die durch Impfung hervorgerufene
Immunantwort gegen Kuhpocken schützt also auch gegen Menschenpocken, ohne dass ein Risiko besteht zu erkranken. Die künstliche Abschwächung von Mikroorganismen zur Nutzung als Impfstoffe gelang Louis Pasteur Ende des 19. Jahrhunderts mit den Erregern des Milzbrandes, der Geflügelcholera und der Tollwut.

Auch Pasteur mangelte es allerdings noch an Kenntnissen über die immunologischen Mechanismen, die der Wirksamkeit der Impfstoffe zugrunde liegen. Erst Emil Behring, der zusammen mit Shibasaburo Kitasato und Fritz Wernecke die passive Impfung gegen Tetanus beziehungsweise Diphtherie entwickelte, fand heraus, dass Blutstoffe - die Antikörper Träger der übertragenen Immunität waren. Dieses Wissen wurde von Behrings Kollegen Paul Ehrlich vervollständigt, der mit der Seitenkettentheorie die spezifische humorale Immunität beschrieb und damit als Entdecker der erworbenen/adaptiven Immunität gilt. Streng genommen führte also die Impfstoff-Forschung zum Wissenschaftszweig der Immunologie und nicht umgekehrt.

Bis vor Kurzem konnten neue Impfstoffe weitgehend unabhängig vom rasant zunehmenden Erkenntnisgewinn in der Immunologie entwickelt werden. Im Prinzip beruhen sie alle auf der Stimulation von Antikörpern, die den eindringenden Erreger beziehungsweise seine Gifte unschädlich machen. Bei den gegen- wärtig bedeutendsten Infektionskrankheiten, gegen die es noch keine Impfstoffe gibt, greift dieses Prinzip aber nicht. Hier müssen wir erst verstehen, wie die gegen sie gerichtete schützende Immunantwort abläuft, um, darauf aufbauend, Impfstoffe zu konzipieren, die eine solche oder bessere Immunantwort hervorrufen.

\section{Impfstoffe, ihre Erfolge gegen Infektionskrankheiten und ihre Grenzen}

Impfstoffe haben weltweit dafür gesorgt, dass viele Infektionskrankheiten heute kontrolliert werden können, eine sogar eliminiert wurde und zwei vor der Eliminierung stehen ([1], • Tab. 1). Folgerichtig werden viele Impfungen von der Ständigen Impfkommission (STIKO) empfohlen (http://www.rki.de) (gegen Diphtherie, Keuchhusten (Pertussis), Tetanus, Haemophilus influenza Typ B (HIB), Hepatitis B, Kinderlähmung (Poliomyelitis), Pneumokokken, Meningokokken, Masern, Mumps, Röteln, humane Papillomaviren (HPV) und Varizellen sowie für Senioren gegen Influenza und Pneumokokken). Sie tragen regelmäßig dazu bei, Epidemien zu verhindern.

Laut Schätzungen der WHO haben im Jahre 2007 weltweit 105 Millionen Kinder den Impfstoff gegen Diphtherie-Tetanus-Pertussis (DTP-Impfstoff) erhalten, sodass global bereits $81 \%$ der Kinder 


\begin{tabular}{|c|c|c|c|c|}
\hline \multirow[t]{2}{*}{ Infektionskrankheit } & \multirow[t]{2}{*}{ Erreger } & Welt & Europa & $\begin{array}{l}\text { Afrika und } \\
\text { Südost-Asien }\end{array}$ \\
\hline & & \multicolumn{3}{|c|}{ Todesfälle in 1000} \\
\hline Tuberkulose & Mycobacterium tuberculosis & 1464 & 77 & 924 \\
\hline AIDS & HIV & 2040 & 31 & 1857 \\
\hline Malaria & Plasmodium falciparum & 889 & 0 & 842 \\
\hline $\begin{array}{l}\text { Durchfallserkran- } \\
\text { kungen }\end{array}$ & $\begin{array}{l}\text { Verschiedene Viren (zum Beispiel } \\
\text { Rotavirus) und Bakterien } \\
\text { (zum Beispiel ETEC) }\end{array}$ & 2163 & 39 & 1689 \\
\hline Syphilis & Treponema pallidum & 99 & 0 & 78 \\
\hline Pertussis & Bordetella pertussis & 254 & 0 & 218 \\
\hline Poliomyelitis & Poliovirus & 1 & 0 & 1 \\
\hline Diphtherie & Corynebacterium diphtheriae & 5 & 0 & 4 \\
\hline Masern & Masernvirus & 424 & 0 & 373 \\
\hline Tetanus & Clostridium tetani & 163 & 0 & 123 \\
\hline Meningitis & $\begin{array}{l}\text { Verschiedene Viren (zum } \\
\text { Beispiel Varizella-Zoster-Virus) } \\
\text { und Bakterien (zum Beispiel } \\
\text { Neisseria meningitidis) }\end{array}$ & 340 & 11 & 259 \\
\hline Hepatitis B & HBV & 105 & 7 & 49 \\
\hline Hepatitis C & $\mathrm{HCV}$ & 54 & 5 & 19 \\
\hline Dengue & Dengue-Virus & 18 & 0 & 11 \\
\hline $\begin{array}{l}\text { Japanische Enze- } \\
\text { phalitis }\end{array}$ & JEV & 11 & 0 & 8 \\
\hline $\begin{array}{l}\text { Untere Atem- } \\
\text { wegsinfektionen }\end{array}$ & $\begin{array}{l}\text { Zum Beispiel Streptococcus } \\
\text { pneumoniae }\end{array}$ & 4177 & 235 & 2812 \\
\hline $\begin{array}{l}\text { Obere Atemwegsin- } \\
\text { fektionen }\end{array}$ & $\begin{array}{l}\text { Zum Beispiel Rhinoviren, } \\
\text { Streptococcus pyogenes }\end{array}$ & 77 & 37 & 9 \\
\hline Otitis media & $\begin{array}{l}\text { Zum Beispiel Streptococcus pneumoni- } \\
\text { ae, Haemophilus influenzae }\end{array}$ & 5 & 0 & 4 \\
\hline
\end{tabular}

durch diese Impfung geschützt wurden. Ähnlich erfolgreich ist auch das Impfprogramm gegen Masern, denn $82 \%$ der Kinder wurden bis zu ihrem zweiten Geburtstag gegen Masern geimpft. Impfstoffe gegen HIB, Röteln, Mumps und Hepatitis B wurden bis 2007 in 115, 126, 114 beziehungsweise 171 Ländern eingeführt (Global Immunisation Data January 2009, WHO und Unicef). Das seit 1988 bestehende Programm zur Ausrottung der Poliomyelitis hat dazu geführt, dass sie weltweit nur noch in wenigen Ländern auftritt (unter anderem in Indien, Nigeria, Afghanistan, and Pakistan) und im Jahr 2008 weniger als 1700 Fälle registriert wurden [2]. Die bisher größte Erfolgsgeschichte ist aber zweifelsohne die Ausrottung der Pocken, die offiziell 1980 durch die WHO erklärt werden konnte [3].

Obwohl viele der genannten Impfungen schon in den meisten Ländern angeboten werden, starben laut Schätzungen der WHO im Jahr 2002 noch 2,5 Milli- onen Kinder an übertragbaren Krankheiten. Ihr Tod hätte durch Impfung oft verhindert werden können (Global Immunisation Data January 2009, WHO und Unicef; • Tab. 1). Die Gründe für diese hohen Mortalitätsraten liegen häufig in der mangelnden Verfügbarkeit der Impfstoffe in den Entwicklungsländern, an den hohen Kosten, die mit einem globalen Immunisierungsprogramm verbunden sind (Polio: bisher zirka sechs Mrd. \$) oder auch an der fehlenden Bereitschaft verschiedener Länder, den Impfstoff einzuführen. Weiterhin ist die Wirksamkeit mancher Impfstoffe durch die hohe Variabilität der Erreger limitiert (zum Beispiel Pneumokokken und Grippeviren). Und letztendlich sollte erwähnt werden, dass nicht alle Impfstoffe in den unterschiedlichen Zielpopulationen (zum Beispiel ältere und immungeschwächte Personen oder chronisch Kranke) eine effektive Immunantwort hervorrufen. Daher muss es das Ziel sein, neue Impfstoffe, Adjuvanzi- en und Impfstrategien zu entwickeln, um diesen Problemen begegnen zu können.

\section{Warum gibt es nicht für alle Infektionskrankheiten Impfstoffe?}

Ungeachtet der oben dargestellten immensen Erfolge im Kampf gegen Infektionskrankheiten gibt es viele Krankheitserreger, gegen die es trotz modernster Techniken und Erkenntnisse keine schützende Impfung gibt. $\mathrm{Zu}$ diesen gefährlichen $\mathrm{Pa}$ thogenen zählen Viren wie das Hepatitis-C-Virus (HCV), das Cytomegalovirus (CMV) und das Humane Immunodefizienz Virus (HIV) oder Bakterien wie Pseudomonas aeruginosa, Staphylococcus aureus, Clostridium difficile und Treponema pallidum (- Tab. 2). Die Ursachen für den Mangel an verfügbaren Impfstoffen gegen diese Erreger können sehr unterschiedlich sein. Angefangen von den Schwierigkeiten, einen pathogenen Organismus (wie zum Beispiel Treponema pallidum, den Erreger der Syphilis) in vitro zu kultivieren, kann die Existenz verschiedener Serotypen (wie bei den Streptokokken) oder die außerordentliche Diversität von Viren (wie von HCV oder HIV) sowie ihre Fähigkeit, in infizierten Patienten zu mutieren, die Entwicklung eines Impfstoffes erschweren.

Manche Mikroorganismen haben zudem Mechanismen entwickelt, um die menschliche Immunabwehr zu umgehen, zu modulieren oder abzuschwächen. Während Viren wie Herpes Simplex Virus (HSV), HIV oder HCV Strategien einsetzen, um dem Angriff durch das Immunsystem zu entkommen oder die Immunantwort zu modulieren (zur Übersicht $[4,5])$, produzieren Pathogene wie etwa S. aureus oder Streptococcus pyogenes zusätzlich vielfältige Virulenzfaktoren, die das Immunsystem schwächen oder außer Kraft setzen (zur Übersicht $[6,7]$ ).

Ein weiteres Hindernis ist, dass der Einsatz inaktivierter Pathogene als Impfstoffe - wie in den traditionellen Totimpfstoffen (zum Beispiel gegen das Grippevirus, Hepatitis-A-Virus) - für manche Erreger (zum Beispiel S. pyogenes) nicht möglich ist, da Komponenten der Erreger beim Menschen schwere Nebenwirkungen auslösen können [8]. Die Ent- 
wicklung von Impfstoffen gegen diese Gruppe von Mikroorganismen wurde in den letzten beiden Jahrzehnten erst durch den Einsatz moderner Methoden zur Entwicklung von Untereinheitenimpfstoffen möglich.

\section{Infektionskrankheiten, für die es keine Impfstoffe gibt}

\section{Infektionskrankheiten in den Entwicklungsländern}

Tuberkulose. Die WHO schätzt, dass jährlich weltweit zirka 1,7 Millionen Menschen an Tuberkulose (TB) sterben und insgesamt zwei Milliarden Menschen - also ungefähr ein Drittel der Weltbevölkerung - mit dem TB-Erreger Mycobacterium tuberculosis infiziert sind. Von diesen Infizierten müssen jedes Jahr ungefähr neun Millionen Menschen behandelt werden, da sie neu an TB erkranken. Die TBErkrankungszahlen sind zwar in allen Regionen der Erde, außer in den WHO-Regionen Europas, erstmals gesunken oder stabil geblieben (Tuberkulose-Report für 2006, WHO), aber die Zahl der jährlichen Neuerkrankungen erreicht in Subsahara-Afrika noch immer bis zu 350 Fälle auf 100.000 Einwohner. In Deutschland wurden im Jahre 2007 insgesamt 5020 TBFälle registriert, was 6,1 Neuerkrankungen pro 100.000 Einwohner entspricht (Epidemiologie der Tuberkulose in Deutschland im Jahr 2007, RKI, Berlin, 2009). Da die Wirksamkeit des einzig verfügbaren TB-Impfstoffes - BCG - nicht belegbar ist und zudem unerwünschte Nebenwirkungen beobachtet wurden, wird eine BCG-Impfung seit 1998 in Deutschland nicht mehr von der STIKO empfohlen.

HIV-Infektionen. HIV ist ein Retrovirus, das die Zellen des menschlichen Immunsystems zerstört und dessen Funktion immer weiter schwächt, sodass die Betroffenen besonders anfällig für Infektionen durch andere Erreger werden. Im fortgeschrittenen Stadium der Infektion, oft erst nach zehn bis 15 Jahren entwickelt sich AIDS (acquired immunodeficiency syndrome). Trotz intensiver Forschung ist es bisher nicht gelungen, einen Impfstoff $\mathrm{zu}$ entwickeln, der vor der HIV-Infektion beziehungsweise AIDS schützt. Daher kön-

Bundesgesundheitsbl 2009·52:1069-1082 DOI 10.1007/s00103-009-0951-0

(c) Springer-Verlag 2009

\section{S.H.E. Kaufmann · A.L. Meinke · A. von Gabain}

Neue Impfstoffkonzepte auf Basis moderner Erkenntnisse der Immunologie

\section{Zusammenfassung}

Seit ihrer Einführung vor mehr als 200 Jahren haben Impfstoffe viele Millionen Todesfälle durch Infektionskrankheiten verhindert. Diese Entwicklung war möglich, da die Wirkweise dieser Impfstoffe vorwiegend auf schützenden Antikörpern beruht, die relativ leicht stimuliert werden können. Inzwischen hat man erkannt, dass Krankheiten wie AIDS, Tuberkulose, Malaria und Hepatitis $\mathrm{C}$ mit diesen traditionellen Ansätzen nicht beizukommen ist. Die modernen Erkenntnisse der Immunologie bieten die Grundlage für den Einsatz maßgeschneiderter Impfstoffe und somit für die erfolgreiche Bekämpfung dieser bedrohlichen Infektionskrankheiten. Moderne Vakzine enthalten Komponenten, die alle Träger

\section{Novel vaccination concepts on the basis of modern insights into immunology}

\section{Abstract}

Since their introduction more than 200 years ago, vaccines have prevented millions of deaths caused by infectious diseases. This progress was possible because these vaccines protect through antibodies, which are relatively easily stimulated. In the meantime, we understand that diseases such as AIDS, tuberculosis, malaria and hepatitis $C$ cannot be tackled by these conventional approaches. Recent insights into immunology provide the basis for the development of custom-tailored vaccines to successfully combat these threatening infections. These new generation vaccines comprise components that mod- der Immunität, das heißt B-Zellen, T-Zellen, antigenpräsentierende Zellen und Zytokine, so modulieren, dass sich die bestmögliche Antwort entwickelt. Neue Applikationsverfahren bieten die Möglichkeit, die Immunantwort weiter zu verbessern. Somit besteht berechtigte Hoffnung, dass mit dem enormen Wissenssprung in der Immunologie und der Infektionsforschung die Herausforderungen durch Infektionskrankheiten gemeistert werden können.

Schlüsselwörter Impfstoff · Immunität · Antikörper · Antigen · T-Lymphozyt ulate the mediators of immunity ( $B$ cells, $T$ cells, antigen-presenting cells and cytokines) in such a way that the best possible immune response develops. Alternative application methods offer the possibility to further improve the immune response. Thus, hope remains that the remarkable increase in knowledge in the areas of immunology and infectious disease research will help to successfully control infectious diseases.

\section{Keywords} Vaccine $\cdot$ Immunity $\cdot$ Antibody $\cdot$ Antigen $\cdot T$ lymphocyte 


\begin{tabular}{|c|c|c|c|}
\hline Erreger & Krankheit $^{\mathrm{a}}$ & Behandlung $^{b}$ & Forschung $^{c}$ \\
\hline Borrelia burgdorferi & Borreliose & Antibiotika & Präklinisch \\
\hline Calicivirus, Norovirus (NoV) & Diarrhö & Keine spezifische & Präklinisch \\
\hline Campylobacter jejuni & Diarrhö & & Präklinisch \\
\hline Candida albicans & Infektion der Schleimhäute & Antifungizide & Phase I-II \\
\hline Chlamydia sp. & Geschlechtskrankheit & Antibiotika & Präklinisch \\
\hline Clostridium difficile & Diarrhö & Antibiotika & Phase II \\
\hline Dengue-Virus & Grippeähnlich & Keine spezifische & Phase I-II \\
\hline ETEC & Diarrhö & Antibiotika & Phase II \\
\hline Hepatitis-C-Virus (HCV) & Asymptomatisch, Leberzirrhose, -krebs & Ribavirin/Interferon & Phase I-II \\
\hline Helicobacter pylori & Gastritis & Antibiotika & Phase I \\
\hline Herpes simplex virus type 1, 2 (HSV) & $\begin{array}{l}\text { Bläschenbildung, Infektion von Haut, } \\
\text { Auge, Genitalien }\end{array}$ & Keine & Phase II-III \\
\hline Humanes Immundefizienz-Virus (HIV) & AIDS & $\begin{array}{l}\text { Antiretrovirale } \\
\text { Therapie }\end{array}$ & Präklinische Phase I-III \\
\hline Leishmania Spezies & Hautgeschwüre & $\begin{array}{l}\text { Antimonials, } \\
\text { Miltefosin }\end{array}$ & Phase I \\
\hline Mycobacterium tuberculosis & Tuberkulose & Antibiotika & Phase II \\
\hline Mycobacterium ulcerans & Hautgeschwür & & Präklinisch \\
\hline Neisseria gonorrhoeae & Gonorrhö & Antibiotika & Präklinisch \\
\hline Neisseria meningitidis $B$ & Meningitis & Antibiotika & Phase II \\
\hline Plasmodium falciparum & Malaria & Anti-Malariamittel & Phase I-II \\
\hline Pseudomonas aeruginosa & Pneumonien, Infektion auf Brandwunden & Antibiotika & Phase II \\
\hline Respiratory syncytial virus (RSV) & Atemwegserkrankung & Keine & Phase II \\
\hline Shigella Spezies & Diarrhö & Antibiotika & Phase I-III \\
\hline Staphylococcus aureus & $\begin{array}{l}\text { Lungenentzündung, toxisches Schock-Syndrom, } \\
\text { Sepsis }\end{array}$ & Antibiotika & Phase II \\
\hline Streptococcus pyogenes & Rachenentzündung & Antibiotika & Phase II \\
\hline Treponema pallidum & Syphilis & Antibiotika & Präklinisch \\
\hline West-Nil-Virus & Influenzaähnlich & Keine & Phase I \\
\hline
\end{tabular}

nen infizierte Personen derzeit nur mittels antiretroviraler Therapie (ART) behandelt werden. Weltweit sind ungefähr 33 Millionen Menschen mit HIV infiziert. Die Rate der Neuinfektionen liegt gegenwärtig bei zirka 6800 Personen pro Tag, und mehr als zwei Millionen Menschen erliegen jährlich der Krankheit AIDS. Während in West- und Zentraleuropa zirka zwei Millionen Menschen HIV tragen [AIDS epidemic update 2007, Joint United Nations Programme on HIV/AIDS (UNAIDS) and WHO, 2007], ist ähnlich wie für die TB die Subsahara-Region am stärksten betroffen. Mehr als zwei Drittel der positiv auf HIV getesteten Menschen leben in dieser Region. Von ihnen haben nur ungefähr drei Millionen Menschen Zugang zu ART.

Die Ko-Infektion HIV-Infizierter mit M. tuberculosis ist tödlich. HIV schwächt das Immunsystem, sodass die TB die häu- figste Todesursache bei HIV-Infizierten in Afrika ist. Zudem begünstigt die große Zahl an immungeschwächten HIV-Infizierten die dort beobachtete rasche Verbreitung der TB. Daher ist die Entwicklung effektiver Impfstoffe und/oder Therapien für beide Krankheiten von außerordentlicher Bedeutung.

Malaria. Eines der größten Gesundheitsprobleme in den Entwicklungsländern ist die Malaria, an der 2006 weltweit 247 Millionen Menschen erkrankten und 880.00o Menschen, vor allem Kinder, starben, obwohl sie heil- und verhinderbar ist. Die Krankheit kann durch fünf verschiedene Spezies des Parasiten Plasmodium ( $P$. falciparum, $P$. vivax, $P$. malariae, $P$. ovale und $P$. knowlesi) verursacht werden, die durch infizierte Moskitos übertragen werden. Im Jahre 2006 wurde die Malaria aus 109 Ländern der Welt gemeldet, wobei die meisten Krankheitsund Todesfälle in der afrikanischen Subsahara-Zone auftraten. Die frühzeitige Behandlung mit einer Kombination von Medikamenten fördert die Genesung. Allerdings verschlingt die Behandlung in manchen Ländern bis zu 40\% der öffentlichen Gesundheitsausgaben. Malaria betrifft vor allem arme Menschen oder Menschen, die keinen Zugang zu Medikamenten haben.

Durchfallerkrankungen. Die Infektionskrankheiten mit der zweitgrößten Zahl an Todesfällen (weltweit zirka zwei Millionen Todesfälle pro Jahr) sind Durchfallerkrankungen. Nur die Zahl der Todesfälle aufgrund von Infektionen der unteren Atemwege ist größer (• Tab. 1). Von infektiösen Durchfallerkrankungen sind vorwiegend Kinder in den Entwicklungsländern betroffen. Jährlich leiden vermutlich zir- 
ka vier Milliarden Menschen an Durchfall oder Nahrungsmittelvergiftungen. Die Erreger werden durch kontaminierte Lebensmittel, Getränke oder Wasser oder über Schmierinfektionen verbreitet. Meist ausgelöst durch eine Infektion im MagenDarm-Bereich, sind Durchfallerkrankungen dadurch charakterisiert, dass die Erkrankten mindestens dreimal am Tag flüssigen Stuhl verlieren. Zu den häufigsten Verursachern von Durchfallerkrankungen gehören unter anderem Rotaviren, Noroviren, enterotoxische E. coli (ETEC), Vibrio cholerae sowie Shigella- und Salmonella-Spezies. Derzeit gibt es nur wenige Impfstoffe gegen Durchfallerkrankungen (zum Beispiel Rotarix und Rotateq gegen Rotavirus sowie Dukoral gegen Cholera, der auch beansprucht, partiellen Schutz gegen ETEC-Infektionen zu bieten).

\section{Nosokomiale Erreger und Antibiotikaresistenzen}

Staphylokokken. Bereits im Jahr 1884 beschrieb Rosenbach zwei unterschiedlich pigmentierte kugelförmige Bakterienkolonien, die er Staphylococcus aureus (S. aureus) und S. albus (heute epidermidis) nannte. Heute weiß man, dass $S$. aureus bei 25$30 \%$ aller Menschen in der Nase und bei vielen Menschen auf der Haut vorkommt und dort in der Regel keine Krankheitssymptome auslöst. S. aureus ist aber auch der häufigste Erreger nosokomialer Infektionen. Weltweit leiden zu jedem Zeitpunkt ungefähr 1,4 Millionen Menschen an Nosokomialinfektionen. Ist die Immunabwehr eines Menschen gestört oder zum Beispiel nach Operationen, Implantationen oder dem Einsatz von Prothesen unterdrückt, kann es zu schweren Infektionen durch S. aureus kommen [Hautinfektionen, Lungenentzündung, Endokarditis, toxisches Schock-Syndrom (TSS) und Sepsis]. Die Todesrate bei invasiven S.-aureus-Infektionen liegt trotz Antibiotikaeinsatz noch immer bei bis zu 30\%, und der Behandlungserfolg wird zunehmend durch das Auftreten antibiotikaresistenter Stämme verhindert. Seit 1961 sind Methicillin-resistente S.-aureusStämme (MRSA-Stämme) bekannt, und 2002 wurden erstmalig auch Vancomycin-resistente Stämme (VRSA) beschrieben [9]. Weltweit sind MRSA-Stämme als
Verursacher von Krankenhausinfektionen bekannt - in einigen asiatischen Ländern liegen die Resistenzraten bei 70-80\%. Die zunehmenden Antibiotikaresistenzen erschweren die gezielte Therapie der Erkrankungen erheblich und unterstreichen die Notwendigkeit der Entwicklung präventiver Impfstoffstrategien [10].

Enterokokken. Enterokokken gehören zur normalen Darmflora des Menschen, aber sie können Infektionen zum Beispiel der Harnwege oder Herzklappen verursachen oder sogar eine Sepsis auslösen. Enterokokken sind grampositive Kokken und umfassen mindestens zwölf verschiedene Spezies, die zum Teil gering virulent sind. Ihre Resistenz gegen viele Antibiotika ist jedoch besorgniserregend [11]. Seit einigen Jahren wird die Verbreitung von Enterokokken-Stämmen beobachtet, die gegen Aminopenicilline, Aminoglykoside und Vancomycin resistent sind, aber auch eine natürliche Resistenz gegen Cephalosporine aufweisen. Dabei erreichen die Resistenzen in einigen europäischen Ländern Raten von bis zu 40\% [11]. Eine Behandlung von Infektionen mit diesen mehrfach resistenten Stämmen ist schwierig oder nicht mehr möglich.

Clostridien. Infektionen durch das grampositive, Endosporen bildende Bakterium Clostridium difficile wurden lange Zeit unterschätzt. In den letzten Jahren kam es aber in den USA zu einem drastischen Anstieg der sogenannten „Clostridium difficile-associated disease“ (CDAD) [12]. Auch in Europa wurde über eine zunehmende Morbidität und Mortalität durch C.-difficile-Infektionen berichtet [13], und in Asien wurde zwischen 2001 und 2006 ein vierfacher Anstieg in der Zahl an CDAD beobachtet [14]. Bakterienisolate zeigten dabei Resistenzen unter anderem gegen Erythromycin, Ciprofloxacin und Moxifloxacin. Ausgehend von den Behandlungskosten für einen C.-difficile-Fall, die bei 5000-15.000 EUR liegen, wurde von der ECDC geschätzt, dass in Europa ca. drei Milliarden Euro an Gesamtkosten pro Jahr für die Therapie der CDAD anfallen. Auch das Robert KochInstitut (RKI) meldete für die Jahre 2004 bis 2006 eine Verdoppelung der CDADFälle in Deutschland. Es geht davon aus, dass sich der Trend in den nächsten Jahren fortsetzt.

In den letzten Jahren sind auch die Antibiotikaresistenzraten weiterer Erreger kontinuierlich angestiegen. So wurden auf Intensivstationen für $S$. aureus Resistenzraten gegen Methicillin von $80 \%$, für Enterobacter-Spezies gegen Ceftriaxone von $50 \%$ und für $P$. aeruginosa gegen Fluoroquinolone und Carbapenem von zirka 50\% berichtet [15]. Des Weiteren wurden in Europa bei K. pneumoniae Resistenzraten von ca. $50 \%$ bis $60 \%$ gegen Carbapenem, Quinolone und Cephalosporine der dritten Generation beobachtet.

\section{Ziele neuer Impfungen}

\section{Präventivimpfstoffe zur Verhinderung einer Erkrankung}

Präventivimpfstoffe sollen in der Regel den Geimpften vor dem Ausbruch einer Erkrankung schützen. Die Entwicklung solcher Impfstoffe hat daher in vielen Fällen das Ziel, den Erreger nach erfolgter Infektion in Schach zu halten, um das Auftreten klinischer Krankheitssymptome zu verhindern. Neue Impfstoffe gegen so weit verbreitete und chronische Infektionskrankheiten wie TB, AIDS oder Hepatitis $\mathrm{C}$ zielen daher nicht nur auf die Verhinderung der Infektion selbst, sondern vorrangig darauf, den Ausbruch oder das Fortschreiten der Krankheit bei infizierten Personen und eine Übertragung des Erregers auf andere Menschen zu verhindern - so auch die neuen HIV-Impfstoffe. Alle bisherigen Versuche, diese Ziele mit einem HIV-Impfstoff zu erreichen, sind aber aufgrund der enormen genetischen und antigenen Variabilität des HIV - gescheitert. Das Virus konnte durch die Immunisierung nicht neutralisiert werden, sodass die Zerstörung des Immunsystems nahezu ungehindert fortschritt. Für die erfolgreiche Entwicklung einer HIV-Vakzine wird es daher umso wichtiger sein $\mathrm{zu}$ verstehen, wie das Virus durch immunologische Interventionen an seiner Verbreitung gehindert werden kann [16].

Ähnlich schwierig gestaltet sich die Entwicklung eines HCV-Impfstoffs [17]. Auch für HCV gilt es zu verstehen, warum bisher erprobte Impfstoffe nicht in der La- 
ge waren, eine vorwiegend schützende zelluläre Immunantwort $\mathrm{zu}$ induzieren und das Virus vor Ausbruch einer Erkrankung zu eliminieren.

Infektionen mit dem Bakterium Helicobacter pylori gehören weltweit zu den häufigsten Infektionen des Menschen. Die Infektionsrate liegt in den USA bei zirka 50\%. In Entwicklungsländern sind bis zu $80 \%$ aller Kinder unter zehn Jahren und mehr als 90\% aller Erwachsenen infiziert. Zwar zeigen die meisten Patienten keine Symptome, aber die Infektion kann zu chronischer Gastritis sowie zu Darmund Magengeschwüren führen. Obwohl in Tiermodellen gezeigt werden konnte, dass durch Immunisierung eine schützende Immunantwort hervorgerufen werden kann, sind bisher alle klinischen Prüfungen mit dem Ziel, die latente Infektion mit dem Erreger zu verhindern und die Patienten von der bestehenden Infektion zu befreien, erfolglos geblieben.

\section{Passive Impfungen zur Verhinderung einer Infektion oder Erkrankung}

Impfungen können - wie oben beschrieben - aktiver Natur sein, aber es können auch gegen den Erreger gerichtete Antikörper verabreicht werden. In diesem Fall spricht man von einer passiven Impfung. Natürlicherweise kommt diese Art der Immunisierung während der Schwangerschaft vor, das heißt, hier wird das ungeborene Kind durch den Transfer mütterlicher Antikörper vor einer Infektionskrankheit geschützt.

Während Antikörper in früheren Jahren aus menschlichem oder tierischem Blut gewonnen wurden, basieren passive Impfstoffe heutzutage auf gentechnologisch entwickelten monoklonalen Antikörpern (mAb). Während mAb schon vielfach für die Behandlung von Krankheiten wie Krebs eingesetzt werden, ist bislang nur ein $\mathrm{mAb}$ (Synagis) gegen eine Infektionskrankheit zugelassen [18]: Da eine aktive Impfung gegen Infektionen mit dem Respiratory-Syncytial-Virus (RSV) nicht verfügbar ist, kann das Virus, das Verursacher der häufigsten nosokomialen Infektionen bei Säuglingen und Kleinkindern ist, nur durch eine passive mAb-Immunisierung bekämpft werden. Die passive RSV-Impfung wird Kindern, die in der 35. Schwangerschaftswoche oder früher geboren werden, und Kindern, die zu Beginn der RSV-Saison jünger als sechs Monate sind, empfohlen.

mAb eignen sich auch zur Behandlung einer Infektion, wenn eine aktive Impfung fehlt. Dies trifft vor allem für nosokomiale Infektionen zu, die zunehmend schwerer durch Antibiotika therapierbar sind. So sind verschiedene humane mAb zum Beispiel zur Behandlung nosokomialer Pseudomonas-Lungenentzündungen oder Methicillin-resistenter S.-aureus-Infektionen in der klinischen Entwicklung [19].

\section{Aktive Impfungen \\ gegen nosokomiale, multiresistente Keime}

Nosokomiale Infektionen sind gegenwärtig nahezu nur mit Antibiotika therapierbar. Zukünftig könnten aber betroffene Patienten durch eine Behandlung mit $\mathrm{mAb}$ - vor allem bei Infektionen mit multiresistenten Bakterien - vor schwerwiegenden Erkrankungen oder dem sicheren Tod geschützt werden. Sofern Krankenhausaufenthalte - wie zum Beispiel Operationen - gezielt geplant werden können, sind aber aktive Immunisierungen zum Schutz vor einer Erkrankung durch nosokomiale Keime die beste Vorsorge.

In diesem Zusammenhang sollen hier nur zwei Impfstoffe erwähnt werden, die sich in der klinischen Entwicklung befinden. Sie zielen auf die beiden häufigsten Erreger nosokomialer Infektionen in Krankenhäusern: Es handelt sich um einen Impfstoff gegen $S$. aureus [10] sowie um einen gegen $P$. aeruginosa [20]. Der S.-aureus-Impfstoff V710 wird - nachdem er sich in einer klinischen Phase-I-Untersuchung als sicher und immunogen erwiesen hat - gerade in einer Phase-II-Studie an Patienten mit Herz-Lungen-Operationen getestet (http:// clinicaltrials.gov). P. aeruginosa verursacht im Krankenhaus vor allem Infektionen bei Patienten, die unter Brandverletzungen leiden. Er ist die häufigste Ursache für Pneumonien auf Intensivstationen bei Patienten, die länger als sieben Tage beatmet werden (http://intercell.com). Der IC43-Impfstoff wird in einer Phase-II-Studie an Patienten auf der Intensivstation getestet, die mechanisch beatmet werden. Vom Erfolg solcher Impfstoffe wird es abhängen, ob nosoko- miale Infektionen in Zukunft effektiv bekämpft werden können und den zunehmenden Antibiotikaresistenzen damit Einhalt geboten werden kann.

\section{Präventive Maßnahmen zur Vermeidung von Infektionen}

Die Prävention einer Infektion ist die effektivste Maßnahme zur Vermeidung von Infektionskrankheiten und deren Ausbreitung. Je nach Erreger erfolgt sie auf unterschiedlichen Ebenen. So sind viele Todesfälle vor allem in den Entwicklungsländern aufgrund von Durchfallerkrankungen und in der westlichen Welt durch nosokomiale Infektionen auf kontaminiertes Wasser und Lebensmittel beziehungsweise auf mangelnde Hygiene zurückzuführen. Verbesserungen auf diesen Ebenen können also helfen, Infektionen zu verhindern beziehungsweise zu reduzieren. Ähnlich können Infektionen mit HIV oder HCV durch die Verwendung steriler Nadeln und kontrollierter Blutkonserven unterbunden beziehungsweise verringert werden. Im $\mathrm{Zu}$ sammenspiel mit solchen Präventivmaßnahmen kann oft nur eine Impfung, die eine Infektion verhindert, dazu führen, dass ein Erreger gänzlich eliminiert wird, so wie es für das Pockenvirus gelungen ist. Ein idealer Impfstoff verhindert also bereits die Infektion mit einem Erreger und unterbindet so jede weitere Übertragung auf andere nicht immune Personen.

\section{Immunologische Grundlagen}

\section{Schnelldurchgang durch die Immunologie}

Die Komplexität des Immunsystems ist verblüffend und noch lange nicht vollständig aufgeklärt. Hier soll versucht werden, die wichtigsten Immunmechanismen, die für ein Verständnis des impfinduzierten Schutzes benötigt werden, in vereinfachter, aber möglichst präziser Form darzustellen [21]. Die Immunität ruht auf zwei Säulen. Die angeborene Immunität ist für die frühe Abwehr von Krankheitserregern verantwortlich. Das angeborene Immunsystem erkennt spezifisch Erregerstrukturen, die ihm eine erste Abschätzung der Erregertypen ermöglicht. 
Das Erkennen von Krankheitserregern führt zur direkten Mobilisierung von Abwehrkräften. Hierzu zählen das Komplementsystem, das die direkte Abtötung von Keimen und das Anlocken von Entzündungszellen bewirkt, sowie das Interferonsystem als antivirales Abwehrsystem. Die wichtigsten zellulären Vertreter der angeborenen Immunität sind die Phagozyten: die kurzlebigen neutrophilen Granulozyten und die langlebigen mononukleären Phagozyten, also die Monozyten und Makrophagen. Diese Zellen können Krankheitserreger aufnehmen (phagozytieren) und viele von ihnen abtöten.

Zeitlich folgt auf die angeborene Immunantwort die erworbene/adaptive Immunantwort, die sich durch eine hohe Spezifität auszeichnet. Träger der erworbenen/adaptiven spezifischen Immunität sind die Lymphozyten. Die B-Lymphozyten produzieren Antikörper, die sie in die Umgebung sezernieren. T-Lymphozyten erkennen Erreger über einen zellständigen Rezeptor, der als T-Zellrezeptor bezeichnet wird. Jede B- und T-Zelle besitzt jeweils nur einen spezifischen Antigen-Rezeptor. Eine antigenspezifische Stimulation bewirkt die klonale Expansion der Lymphozyten mit dem entsprechenden homologen Rezeptor. Dadurch können mehr Zellen auf das Antigen reagieren und auf diese Weise den Erreger bekämpfen. Sowohl B- als auch T-Lymphozyten können ein immunologisches Gedächtnis ausbilden: Auf Zweitkontakt mit dem gleichen oder einem nahe verwandten Erreger reagieren sie schneller und effektiver. Das spezifische Gedächtnis der erworbenen Immunität ist der grundlegende Mechanismus der Impfung.

Weder B-Zellen noch T-Zellen stellen eine funktionell einheitliche Gruppe dar. B-Zellen produzieren unterschiedliche Antikörperklassen, die unterschiedliche Funktionen wahrnehmen (• Tab. 4). Für die Impfung sind am wichtigsten die Immunglobuline (Ig) der Klasse IgG als bedeutendste Antikörper des Blutes und IgA als bedeutendste Antikörper der Schleimhäute.

Die T-Lymphozyten lassen sich in zytolytische T-Zellen (ZTL) und T-Helfer(TH-)Zellen unterteilen. Die TH-Zellen tragen als charakteristisches Oberflächenmolekül den CD4-Marker, die ZTL den CD8-Marker. Die ZTL lysieren infizierte Zellen und sind insbesondere für die Virusabwehr verantwortlich. Durch die Zerstörung befallener Zellen können sich die Viren nicht mehr vermehren. THZellen produzieren lösliche Botenstoffe (sogenannte Zytokine), die andere Zellen aktivieren und sie so in die Lage versetzen, Abwehrfunktionen auszuüben. TH1Zellen sind zur Aktivierung von Makrophagen befähigt und übernehmen daher wichtige Aufgaben bei der antibakteriellen Infektabwehr. TH2-Zellen aktivieren eosinophile und basophile Granulozyten und sind daher für die Abwehr von Wurminfektionen verantwortlich. TH2-Zellen produzieren zudem Botenstoffe, die B-Zellen zur Reifung anregen. Sie kontrollieren somit auch die Antikörperantwort. Der Wechsel zu einer bestimmten Antikörperklasse wird wiederum von Botenstoffen der TH1-Zellen und TH2-Zellen reguliert. Die erst kürzlich beschriebenen TH17-Zellen locken Phagozyten an die Eintrittspforte von Erregern. Ihre Bedeutung für die impfinduzierte Immunität ist noch weitgehend unklar. Die regulatorischen $\mathrm{T}-\left(\mathrm{T}_{\text {reg }}\right)$-Zellen wirken den genannten TH-Zellen entgegen. Sie sind für die Beendigung einer Immunantwort nach Erreger-Elimination verantwortlich und verhindern auf diese Weise Schäden durch eine unkontrollierte Immunantwort.

\section{Wie die angeborene Immunität die erworbene/adaptive Immunität instruiert}

Die erworbene Immunität lässt sich nach dem oben dargestellten Muster leicht in einzelne Komponenten zerlegen [22, 23]. Dies ist für ihr Verständnis sinnvoll, wird aber der Komplexität und Plastizität des Immunsystems nicht gerecht. Die erworbene Immunität reagiert nicht nur antigenspezifisch auf einen Erreger. Sie passt sich auch weitgehend dem Erregertyp an. Dies ist für moderne Impfstoffkonzepte von großer Bedeutung. Zwar ist generell akzeptiert, dass Impfstoffe Antigene des Erregers, gegen den sie gerichtet sind, enthalten müssen. Weniger verstanden wird aber, wie ein Impfstoff die für einen bestimmten Erregertyp effektivste Immunantwort hervorruft. In der Tat sind un- sere Kenntnisse auf diesem Gebiet jung, und erst seit wenigen Jahren wissen wir, wie das Immunsystem eindringende Erreger „abtastet“ und so den Erregertyp ermittelt: Dies ist Aufgabe des angeborenen Immunsystems, das somit nicht nur als erste Abwehrfront gegen Erreger dient, sondern auch die erworbene Immunität über den eindringenden Erregertyp informiert.

Für das Erkennen mikrobieller Strukturen oder Muster sind in erster Linie die Toll-ähnlichen Rezeptoren (toll-like receptors, TLR) verantwortlich. Diese TLR sind Oberflächenrezeptoren auf Makrophagen und dendritischen Zellen, die als antigenpräsentierende Zellen (APZ) den T-Lymphozyten Antigene darbieten. Neben diesen Oberflächenrezeptoren kennen wir auch intrazelluläre mustererkennende Rezeptoren, die sogenannten NOD-ähnlichen Rezeptoren (NOD-like receptors, NLR). Bekannt sind mehr als 10 TLR und 20 NLR. Im Folgenden sollen beispielhaft einige TLR und ihre Liganden genannt werden.

Die TLR2 treten als Homodimere und Heterodimere mit anderen TLR auf. Sie sind für das Erkennen bakterieller Lipoproteine, Lipoarabinomannane und Lipoteichonsäuren zuständig. Sie erkennen auch Zymosan von Pilzen. TLR4 erkennt LPS der Enterobakterien, zu denen unterschiedliche Erreger von Durchfallerkrankungen zählen. TLR5 erkennt das Flagellin begeißelter Bakterien und TLR11 Profilin von Protozoen. TLR3, TLR7 und TLR8 sind in erster Linie für das Erkennen viraler RNS verantwortlich: TLR 3 erkennt virale Doppelstrang-RNS, während TLR7 und TLR8 Einzelstrang-RNS von Viren erkennen. TLR9 erkennt bakterielle DNS-Motive, die eine geringe Methylierung aufweisen (sogenannte CpG Motive). Das Erkennen der genannten Erregerstrukturen löst eine Signalkaskade aus, die zur Reifung der APZ führt und sie nun in die Lage versetzt, T-Lymphozyten nicht nur antigenspezifisch zu stimulieren, sondern sie auch über den Erregertyp zu informieren. Es ist offensichtlich, dass die Aufklärung dieser Mechanismen für die Entwicklung neuer Adjuvanzien von herausragender Bedeutung ist. 


\begin{tabular}{|c|c|c|c|}
\hline $\begin{array}{l}\text { Bezeich- } \\
\text { nung }\end{array}$ & Wichtige Funktion & Wichtiger Produzent & Wichtige Zielzelle \\
\hline IL-2 & T-Zellstimulation & T-Zellen & T-Zellen \\
\hline IL-4 & $\begin{array}{l}\text { B-Zellaktivierung, Klassenwechsel } \\
\text { zu lgE, Aktivierung von Basophilen }\end{array}$ & TH2-Zellen & B-Zellen \\
\hline IL-5 & $\begin{array}{l}\text { B-Zellreifung, } \\
\text { Klassenwechsel zu lgA, Aktivierung } \\
\text { von Eosinophilen }\end{array}$ & TH2-Zellen & $\begin{array}{l}\text { B-Zellen, } \\
\text { Eosinophile }\end{array}$ \\
\hline IL-10 & Suppression & $\begin{array}{l}\text { TH2-Zellen, } \\
\mathrm{T}_{\text {reg-Zellen }}\end{array}$ & Makrophagen \\
\hline IL-12 & Aktivierung von TH1-Zellen und ZTL & $\begin{array}{l}\text { Makrophagen, } \\
\text { dendritische Zellen }\end{array}$ & T-Zellen \\
\hline IL-17 & $\begin{array}{l}\text { Entzündung, Aktivierung von } \\
\text { Neutrophilen }\end{array}$ & TH17-Zellen & Neutrophile \\
\hline IFN- $\gamma$ & $\begin{array}{l}\text { Makrophagenaktivierung, } \\
\text { Klassenwechsel zu opsonisierenden } \\
\text { Antikörpern }\end{array}$ & TH1-Zellen & $\begin{array}{l}\text { Makrophagen, } \\
\text { B-Zellen }\end{array}$ \\
\hline TGF- $\beta$ & Suppression, Klassenwechsel zu IgA & $\begin{array}{l}T_{\text {reg-Zellen, }} \\
\text { Makrophagen }\end{array}$ & $\begin{array}{l}\text { T-Zellen, } \\
\text { Makrophagen, } \\
\text { B-Zellen }\end{array}$ \\
\hline
\end{tabular}

\section{Antigenpräsentation und Stimulation von TH-Zellen und ZTL}

APZ umfassen Makrophagen, B-Zellen und dendritische Zellen. Am effektivsten sind die dendritischen Zellen, insbesondere für die Präsentation löslicher Proteinantigene. Makrophagen besitzen eine hohe Phagozytose-Aktivität und können daher bakterielle Erreger sehr effizient aufnehmen, abtöten und abbauen. Bei der Abwehr bakterieller Infektionen wirken Makrophagen und dendritische Zellen häufig zusammen: Makrophagen nehmen Bakterien auf, lysieren diese und durchlaufen dann einen programmierten Zelltod (als Apoptose bezeichnet). Dabei entstehen Vesikel, die Erregerantigene enthalten, die von umgebenden dendritischen Zellen aufgenommen werden können. Dieser als Crosspriming bezeichnete Vorgang ist außerordentlich effektiv, da er die spezifischen Fähigkeiten beider APZ vereint.

Als dritte APZ-Gruppe sind B-Zellen zu nennen, die über ihren Ig-Rezeptor spezifisch Antigene (typischerweise lösliche Proteine) erkennen, aufnehmen und dann präsentieren. Sie sind daher insbesondere bei der Zweitantwort gegen ein dem Immunsystem bereits bekanntes Erregerantigen von Bedeutung.
Lösliche Proteinantigene gelangen über Pinozytose in das endosomale Netzwerk. Dort werden sie in Peptidbausteine zerlegt, die anschließend an Moleküle gekoppelt werden, die von Klasse-II-MHCGenen (MHC: major histocompatibility complex) kodiert werden. Bakterien und Protozoen gelangen nach der Phagozytose ins Phagosom, das heranreift und im reifen Zustand mit Lysosomen verschmilzt. Nach Abtötung und Abbau der Erreger werden die freigesetzten Eiweiße zerlegt und die entstandenen Peptide ebenfalls an MHC-II-Moleküle gebunden. Einige Erreger können die Phagosomenreifung modulieren und dadurch dem Abbau und der Antigenpräsentation zumindest teilweise entgehen. CD4-T-Lymphozyten mit Helferfunktion (CD4 ${ }^{+}-\mathrm{TH}-Z$ Zellen) erkennen antigene Peptide, die von MHCII-Molekülen präsentiert werden. Die MHC-II-Moleküle werden in erster Linie von APZ exprimiert; viele andere Körperzellen sind dazu nicht in der Lage und daher auch nicht zur MHC-II-restringierten Antigenpräsentation befähigt. Virale Erreger können sich in unterschiedlichen Wirtszellen vermehren. Während des $\mathrm{Zu}$ sammenbaus der Viren entstehen „überflüssige“ Proteine, die über das Proteasomensystem in Peptide zerlegt werden. Diese Peptide werden im endoplasmatischen Retikulum auf MHC-I-Moleküle geladen. MHC-I-Moleküle finden sich auf vielen
Körperzellen, sodass die MHC-I-Beladung nicht auf APZ beschränkt ist. CD8T-Lymphozyten mit zytolytischen Funktionen $\left(\mathrm{CD}^{+}{ }^{-} \mathrm{ZTL}\right)$ erkennen antigene Peptide, die von MHC-I-Molekülen präsentiert werden.

Die MHC-Präsentation hat zwei wichtige Funktionen: Erstens garantiert sie, dass Antigene von Erregern, die sich in Zellen aufhalten, für T-Lymphozyten kenntlich werden. Zweitens erwirkt sie die gezielte Stimulation zweier unterschiedlicher Funktionsträger, der ZTLund TH-Zellen. Da der Zusammenbau von Viren unterbunden wird, wenn ihre Zielzellen zerstört werden, sind $\mathrm{CD}^{+}{ }^{+}$ ZTL in erster Linie für die Abwehr viraler Infektionen zuständig. Bakterielle Erreger werden typischerweise von Makrophagen und dendritischen Zellen phagozytiert. Die Stimulation von $\mathrm{CD}_{4}{ }^{+}$-T-Helferzellen ist sinnvoll, weil diese über Botenstoffe, sogenannte Zytokine, weitere Zellen des Immunsystems regulieren. Wichtige Zytokine sind in $\bullet$ Tab. 3 zusammengefasst. Allerdings ist diese Aufteilung weniger eindeutig als ursprünglich postuliert. Viren können auch von APZ phagozytiert werden und auf diese Weise $\mathrm{CD}_{4}{ }^{+}-$ T-Lymphozyten stimulieren. Einige Bakterien und Protozoen gelangen in das Zytoplasma von Wirtszellen, wo ihre Antigene auf MHC-I-Moleküle geladen werden können. Entsprechend werden bei viralen Infektionen neben $\mathrm{CD}^{+}{ }^{+} \mathrm{ZTL}$ auch $\mathrm{CD}_{4}{ }^{+}-\mathrm{TH}-$ Zellen und bei bakteriellen Infektionen neben $\mathrm{CD}_{4}{ }^{+}-\mathrm{TH}$-Zellen auch $\mathrm{CD}^{+}$-ZTL stimuliert. Selbst bakterielle Erreger, die im Phagosom verbleiben, können scheinbar von CD8 ${ }^{+}$-T-Zellen erkannt werden. Hierfür dürfte der als Crosspriming beschriebene Präsentationsweg verantwortlich sein.

\section{TH-Zellpopulationen und Zytokine}

Die sogenannten TH1-Zellen produzieren als Leitzytokin Interferon- $\gamma($ IFN- $\gamma)$, das Makrophagen aktiviert. Intrazelluläre Bakterien überleben häufig in Makrophagen. Die Aktivierung durch IFN- $\gamma$ ermöglicht ihre Abtötung oder zumindest die Einschränkung ihres Wachstums. Des Weiteren stimulieren TH1-Zellen die Reifung und Differenzierung von $\mathrm{CD}^{+}-\mathrm{ZTL}$ 


\begin{tabular}{|c|c|c|c|c|c|}
\hline & $\lg G\left(\lg G_{1}, \lg G_{2}, \lg G_{3}, \lg G_{4}\right)$ & $\lg A$ & $\lg M$ & $\lg D$ & $\lg E$ \\
\hline $\begin{array}{l}\text { Serumkonzentration } \\
(\mathrm{mg} / 100 \mathrm{ml})\end{array}$ & 1300 & 350 & 150 & 3 & 0,03 \\
\hline $\begin{array}{l}\text { Aktivierung des } \\
\text { klassischen } \\
\text { Komplementwegs }\end{array}$ & $\mathrm{Ja}\left(\lg \mathrm{G}_{1}, \lg \mathrm{G}_{2}, \lg \mathrm{G}_{3}\right)$ & Nein & $\mathrm{Ja}$ & Nein & Nein \\
\hline $\begin{array}{l}\text { Aktivierung des } \\
\text { alternativen } \\
\text { Komplementwegs }\end{array}$ & Nein & Ja & Nein & Nein & Nein \\
\hline $\begin{array}{l}\text { Aktivierung von } \\
\text { Zielzellen }\end{array}$ & $\begin{array}{l}\text { Makrophagen, Neutrophile } \\
\left(\operatorname{lgG}_{1}, \lg _{3}\right)\end{array}$ & Nein & Nein & Nein & $\begin{array}{l}\text { Basophile, } \\
\text { Eosinophile }\end{array}$ \\
\hline Besondere Merkmale & $\begin{array}{l}\text { Sekundärantwort, } \\
\text { Präzipitation, Agglutination, } \\
\text { Opsonisierung, } \\
\text { Neutralisation }\end{array}$ & $\begin{array}{l}\text { Lokale Abwehr in } \\
\text { Schleimhäuten }\end{array}$ & $\begin{array}{l}\text { Natürliche Antikörper } \\
\text { der Primärantwort, } \\
\text { Präzipitation, Agglutination, } \\
\text { Neutralisation }\end{array}$ & $\begin{array}{l}\text { Antigenrezeptor } \\
\text { auf B-Zellen }\end{array}$ & $\begin{array}{l}\text { Vermittler der } \\
\text { Sofortallergie }\end{array}$ \\
\hline
\end{tabular}

über die Produktion von IFN- $\gamma$ und IL2. Die von $\mathrm{TH} 2$-Zellen produzierten $\mathrm{Zy}$ tokine IL-4 und IL-5 stimulieren die Reifung von B-Zellen zu Antikörper-produzierenden Plasmazellen. Unter dem Einfluss von Typ-1-Zytokinen entstehen opsonisierende Antikörper, die die Phagozytose verbessern.

Eine erst kürzlich beschriebene T-Zellpopulation produziert IL-17, das unter anderem neutrophile Granulozyten stimuliert; entsprechend heißen diese Zellen TH17-Zellen. Sie lösen Entzündungsreaktionen aus und könnten an der $\mathrm{Ab}$ wehr von bakteriellen Erregern, die akute Krankheitsbilder hervorrufen, beteiligt sein. Schließlich kennen wir regulato-

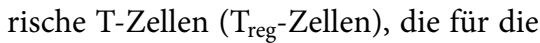
Eindämmung der Immunantwort zuständig sind und Schäden durch ungezügelte Immunreaktionen nach Erregereliminierung vermeiden. Wesentliche Zytokine der $\mathrm{T}_{\text {reg }}$-Zellen sind IL-10 und TGF- $\beta$ (transforming growth factor- $\beta$ ). Die Reifung der unterschiedlichen T-Zellpopulationen wird wiederum von Molekülen gesteuert, die kostimulatorisch oder inhibitorisch wirken und auf der Oberfläche der APZ exprimiert werden. Beteiligt sind ebenfalls Zytokine, die von reifen APZ sezerniert werden. Die wichtigsten T-Zellstimulierenden Zytokine sind in $\bullet$ Tab. 3 genannt. Erwähnt seien IL-12 für die Stimulation von TH1-Zellen, IL-4 für die Stimulation von TH2-Zellen, TGF- $\beta$ für die Aktivierung von $\mathrm{T}_{\text {reg }}$-Zellen und TGF- $\beta$ gemeinsam mit IL-6 für die Aktivierung der TH17-Zellen.
Die kostimulatorischen Moleküle auf APZ gehören unter anderem zur B7-Familie. Ihre Interaktion mit entsprechenden Korezeptoren aufT-Lymphozyten fördern deren Aktivierung oder Hemmung. Das Wechselspiel zwischen APZ und T-Lymphozyten wird über weitere Feinmodulationen, das heißt über Wechselwirkungen zwischen Zytokinen, die von einer T-Zellpopulation produziert werden und andere T-Zellpopulationen beeinflussen, aufrechterhalten, verstärkt oder unterdrückt. So hemmt das von $\mathrm{TH} 2$-Zellen gebildete IL-4 TH1-Zellen, während das von TH1Zellen produzierte IFN- $\gamma \mathrm{TH} 2$-Zellen hemmt. Hohe Konzentrationen an TGF$\beta$, das von $\mathrm{T}_{\text {reg }}$-Zellen gebildet wird, halten die Entwicklung von $\mathrm{T}_{\text {reg-Zellen in Gang, }}$ während niedrige Konzentrationen TH17Zellen stimulieren. Auf TH1-Zellen wirken TGF- $\beta$ sowie IL-10 von $\mathrm{T}_{\text {reg }}$-Zellen dagegen hemmend. Ein besseres Verständnis der komplexen Mechanismen, die für die Aktivierung und Hemmung von T-Zellpopulationen unterschiedlicher Funktionen verantwortlich sind, wird in Zukunft die gezielte Entwicklung von Impfstoffen ermöglichen, die sehr spezifisch eine bestimmte Immunreaktion induzieren. Dies betrifft die noch in den Anfängen stehende Adjuvansentwicklung für neue Untereinheitenimpfstoffe.

\section{T-Zellgedächtnis und Immunsuppression}

Nach Erstkontakt mit ihrem Antigen entwickeln sich T-Zellen zu Effektor-T-Zellen, die zu den oben beschriebenen un- terschiedlichen T-Zellpopulationen heranreifen. Zusätzlich entwickeln sich Gedächtnis-T-Zellen. Hier können zwei Typen unterschieden werden: Zum einen die Effektor-Gedächtnis-T-Zellen, die sich nach Zweitkontakt mit dem homologen Antigen sehr rasch in EffektorT-Zellen umwandeln. Die Effektor-Gedächtnis-T-Zellen halten sich weitgehend in den peripheren Geweben auf und sind daher für die Infektabwehr bestens positioniert. Die Entwicklung von EffektorT-Zellen aus Effektor-Gedächtnis-T-Zellen erfolgt rasch nach Zweitkontakt mit dem Erreger, da dieser Gedächtnis-Zelltyp nach Antigenkontakt direkt EffektorFunktionen ausüben kann. Die zentralen Gedächtnis-T-Zellen finden sich vor allem in den sekundären Lymphorganen. Nach Zweitkontakt mit dem Antigen vermehren auch sie sich und verwandeln sich in Effektor-T-Zellen. Die Bildung von Effektor-T-Zellen aus zentralen GedächtnisT-Zellen benötigt mehr Zeit, da mehrere Replikations- und Reifungsschritte zwischengeschaltet sind.

In enger Definition bedeutet „immunologisches Gedächtnis“ das Vorliegen langlebiger Gedächnis-T-Zellen in Abwesenheit des entsprechenden Antigens. Bei chronischen Infektionen mit kontinuierlichem Antigenstimulus entwickelt sich daher streng genommen kein Gedächtnis im engeren Sinn. In der Tat kann es in diesen Fällen zu einer kontinuierlichen Stimulation von Effektor-T-Zellen kommen, ohne dass sich Gedächtnis-T-Zellen entwickeln können. 
Nach erfolgreicher Bekämpfung einer Infektion gewinnen die $\mathrm{T}_{\text {reg }}$-Zellen an Bedeutung. Ihre Aufgabe ist die Eindämmung der Immunantwort, um Schäden durch eine andauernd aktive Immunreaktion zu vermeiden. Die konstante Präsenz eines Erregers über einen längeren Zeitraum kann auf das Immunsystem als Signal wirken, die Immunantwort zu beenden. Bei chronischen Infektionen wird das Immunsystem daher vor eine schwierige Aufgabe gestellt. Wenn der Erreger persistiert, aber die Infektion keinen Schaden bewirkt, weil das Immunsystem kontrollierend eingreift, könnte die Beendigung der Immunantwort den Krankheitsausbruch erlauben. Für neue Impfkonzepte sind Kenntnisse über Gedächtnis-T-Zellen und $\mathrm{T}_{\text {reg }}$-Zellen von großer Bedeutung, da die Impfung eine möglichst lang andauernde Immunität stimulieren soll, die keine Gewebeschäden hervorruft.

\section{B-Zellen, Antikörper und Gedächtnis}

Antikörper erkennen ihre Antigene direkt. Sie wehren Erreger entweder direkt ab oder mobilisieren Effektormechanismen. Direkte Abwehrmechanismen sind die Blockierung der Anheftung von Viren an Wirtszellen und die Neutralisation von Toxinen. Antikörper der Klasse IgG1 und IgG3 sind zur Opsonisierung befähigt, das heißt, sie verbessern die Keimaufnahme durch Phagozyten (• Tab. 4). Dies ist besonders für die Bekämpfung von Erregern wichtig, die eine Kapsel tragen, wie zum Beispiel Meningokokken oder Pneumokokken. Weiterhin können Antikörper der Klassen IgG1, IgG2, IgG3 und IgM Komplement aktivieren und so Bakterien lysieren, Toxine oder Viren neutralisieren und Entzündungszellen anlocken. In allen diesen Fällen tragen Antikörper indirekt zum Infektionsschutz bei, also über die Mobilisierung von Effektorkaskaden.

Bei diesem breiten Funktionsspektrum verwundert es nicht, dass Antikörper als zentrale Mediatoren aller derzeit verfügbaren Impfstoffe fungieren. Nach Antigenerkennung werden B-Zellen aktiviert und reifen zu kurzlebigen Plasmazellen heran. Sowohl die B-Zellaktivierung als auch der Ig-Klassenwechsel werden von TH-Zellen gesteuert. Plasmazellen produzieren nun große Mengen Antikörper, die die Erregerabwehr übernehmen. Diese Antikörper sind über einen gewissen Zeitraum verfügbar. Die bloße Produktion von Antikörpern durch Plasmazellen gewährt aber keinen langfristigen Schutz, da diese Zellen kurzlebig sind und die Titer der zirkulierenden Antikörper bald absinken. Daneben reifen aktivierte B-Zellen auch zu Gedächtnis-B-Zellen und langlebigen Plasmazellen heran. Die langlebigen Plasmazellen produzieren kontinuierlich Antikörper und garantieren somit über einen langen Zeitraum hinweg hohe Antikörpertiter. Diese sogenannten präexistierenden Antikörper können die eingedrungenen Erreger bei Zweitinfektion direkt angreifen. Nach Zweitkontakt mit dem Antigen reifen die Gedächtnis-B-Zellen zu Plasmazellen heran, die dann die Antikörperantwort verstärken.

\section{Impfstofftypen}

Am Beispiel der Pockenimpfung haben wir in der Einleitung beschrieben, dass diese erste Vakzine rein empirisch entwickelt worden ist. Die Möglichkeit, die Entwicklung von Vakzinen auf eine wissenschaftliche Basis zu stellen, verdanken wir einerseits der Entdeckung von Mikroben als Ursachen übertragbarer Krankheiten und andererseits den durch die Pioniere der Mikrobiologie im 19. Jahrhundert geschaffenen Grundlagen der Immunologie. Dennoch müssen wir uns eingestehen, dass wir auch heute noch oft nicht im Detail erklären können, auf welche Weise zugelassene Impfstoffe schützen und weshalb wir - trotz aller beachtlichen Fortschritte im Verständnis ihrer Wirkmechanismen - häufig bei der Entwicklung neuer Impfstoffe an Grenzen stoßen.

Im Verlauf der Entwicklung von Impfstoffen wurden zwischen dem späten 19. Jahrhundert bis in die 1960er-Jahre folgende Schlüsselerkenntnisse gewonnen:

a) Antigene, das heißt meistens Oberflächenstrukturen oder ausgeschiedene Substanzen von Mikroben, wie mikrobielle Toxine, können als Bestandteile des Impfstoffs eine adaptive Immunantwort anregen. Antikörper, die spezifisch an die Antigene binden, können den Geimpften auf eine spätere Begegnung mit dem Pathogen oder dessen Toxinen vorbereiten. Sie schützen ihn dadurch vor der Auslösung einer ernsthaften Erkrankung.

b) Mikroben oder mikrobielle Bestandteile müssen im Impfstoff so aufbereitet sein, dass nur ein minimales Restrisiko besteht, durch die Impfung eine Erkrankung oder Krankheitssymptome auszulösen.

c) Impfstoffe müssen bei der Impfung eine leichte Entzündung an der Impfstelle oder sogar im Körper anregen, damit die adaptive Immunantwort aktiviert wird und zur Entfaltung kommt.

Folgerichtig enthalten Impfstoffe, die bis in die 196oer-Jahre hinein entwickelt wurden - einige sind bis heute in Verwendung - entweder abgetötete Mikroben - man spricht dann von sogenannten Totimpfstoffen - oder attenuierte (abgeschwächte) Pathogene - es handelt sich dann um sogenannte Lebendimpfstoffe -, die keine Erkrankungen auslösen, aber in leichter Form eine mikrobielle Infektion nachahmen. Die Verwendung bakterieller Toxine als Antigene - zum Beispiel in Impfstoffen gegen Clostridium tetani, Corynebacterium diphtheriae und Vibrio cholerae - ist ein interessanter Sonderweg für Totimpfstoffe [24]. In diesen Fällen neutralisieren die induzierten Antikörper die Wirkung der entsprechenden Toxine, die für die Pathogenität und Virulenz der Erreger entscheidend sind. Deren Inaktivierung verhindert eine Manifestation der Erkrankung.

Die Nutzung von Toxinen als Impfantigene hat eine Entwicklung vorweggenommen, die in jüngster Zeit durch die Fortschritte in den Biomedizinwissenschaften und Produktionsmethoden eine Renaissance erlebt hat. Heute werden möglichst wenige spezifische und selektive Mikrobenstrukturen als Impfantigene eingesetzt. Dagegen hat sich die Verwendung ganzer Bakterien in abgetöteter oder lebender, abgeschwächter Form kaum durchgesetzt. Ein Grund hierfür ist, dass Bakterien, die außerhalb des Körpers unter Laborbedingungen kultiviert werden, oft keine infektionsrelevanten Antigene an der Oberfläche präsentieren und sie daher, wenn sie in Impfstoffen vorliegen, keine schützenden Abwehrkräfte in- 


\begin{tabular}{|c|c|c|c|c|}
\hline & Traditionell & $\begin{array}{l}\text { 1. Innovations- } \\
\text { welle }\end{array}$ & 2. Innovationswelle & Neueste Entwicklungen \\
\hline $\begin{array}{l}\text { Produktions- } \\
\text { methoden }\end{array}$ & $\begin{array}{l}\text { Primäre Bakterienkulturen, } \\
\text { Hühnereier, lebende Tiere }\end{array}$ & $\begin{array}{l}\text { Primäre } \\
\text { Gewebekulturen }\end{array}$ & $\begin{array}{l}\text { Rekombinante Hefen, } \\
\text { rekombinante Bakterien, } \\
\text { Zellkulturen }\end{array}$ & $\begin{array}{l}\text { Synthetisch, zum Beispiel Peptide, } \\
\text { "Carrier Beads" }\end{array}$ \\
\hline Adjuvanzien & Aluminiumsalze & MF59 & $\begin{array}{l}\text { Monophosphoryl-Lipid } \\
\text { (MPL) }\end{array}$ & Iscom, CpG, IC $31^{\oplus}$ \\
\hline $\begin{array}{l}\text { Darbietungs- } \\
\text { systeme }\end{array}$ & $\begin{array}{l}\text { Inaktivierte und abgeschwächte } \\
\text { Mikroben }\end{array}$ & Toxinkonjugate & Virosome & $\begin{array}{l}\text { Virale Kapside, Hitzeschock-Proteine, } \\
\text { heterologe und homologe } \\
\text { rekombinante Vektoren, „Ghosts", } \\
\text { DNA-Vakzine }\end{array}$ \\
\hline Applikation & Intramuskulär, intradermal & Oral & Nasal & Mikronadeln, Pflaster \\
\hline Antigene & $\begin{array}{l}\text { Angereinigte inaktivierte } \\
\text { Toxine }\end{array}$ & Glykoside & Rekombinante Proteine & Peptide \\
\hline
\end{tabular}

duzieren können. Ein Beispiel für einen bakteriellen Impfstoff, der auf einem inaktivierten Erreger aufbaut, ist der Impfstoff gegen Fleckfieber. Hier kommt der inaktivierte bakterielle Erreger, das heißt Rickettsia prowazekii zum Einsatz [25]. Ein historischer bakterieller Lebendimpfstoff, der weiter genutzt wird, ist der gegen die TB gerichtete BCG-Impfstoff. Es handelt sich dabei - ähnlich wie beim Pockenimpfstoff - um einen heterologen Impfstoff bei dem der lebende, aber abgeschwächte Erreger der Rindertuberkulose genutzt wird. Der Impfstoff kann zwar Kinder im Säuglingsalter gegen den meist tödlichen TB-Verlauf einer tuberkulösen Meningitis und einer disseminierten TBForm schützen, er bietet aber keinen ausreichenden Schutz gegen die Lungentuberkulose bei Jugendlichen und im Erwachsenenalter.

Die Entdeckung von Viren als Verursacher von Infektionskrankheiten beschleunigte die Entwicklung effektiver Impfstoffe. Beim Vermehren pathogener Viren unter Laborbedingungen konnten wegen der Plastizität der viralen genetischen Information oft relativ einfach abgeschwächte Virusstämme gezüchtet werden. Diese Virusstämme sind nicht mehr in der Lage, Erkrankungen beim Geimpften auszulösen, sie induzieren aber dennoch Schutz. Solche attenuierten Viren sind zum Beispiel in Impfstoffen gegen Kinderlähmung (Polioviren), Gelbfieber (Flaviviren) oder Mumps (Paramyxoviren) enthalten [26]. Da bei gewissen Pathogenen eine Abschwächung des Impfvirus immer noch zu riskant ist, haben sich auch virale Impfstoffe durchgesetzt, bei denen das Vi- rus durch physikochemische Behandlung inaktiviert wird, um sicherzugehen, dass als Folge der Impfung keine Erkrankung ausgelöst wird. Beispiele dafür sind Impfstoffe gegen das Frühsommer-Enzephalitis- (FSME-)Virus, Tollwut-Virus oder gegen Grippeviren (Influenza-Viren) [26]. Eine Verfeinerung bei viralen Impfstoffen ist die Spaltung der gezüchteten Impfviren in Untereinheiten und die Aufreinigung antigener Strukturen. Damit ist die Zusammensetzung des Impfstoffs genau definiert und eine Virusinaktivierung garantiert, sodass das resultierende Vakzin sicher ist. Allerdings muss im Fall von Grippevakzinen betont werden, dass ihre Immunogenität umso schwächer ist, je höher der Reinheitsgrad des Untereinheitenimpfstoffs ist. Um die Effektivität solcher Grippeimpfstoffe zu verstärken, setzt man ihnen neuerdings Adjuvanzien zu [27].

Die beeindruckenden Fortschritte der letzten Jahrzehnte in der Immunologie, Molekularbiologie, bei genomischen Analyseansätzen und im Verständnis der Wirts-Pathogen-Wechselwirkungen haben es erlaubt, die Entwicklung ganz neuer Impfstoffe in Angriff zu nehmen (• Tab. 5). Sie richten sich gegen jene Krankheitserreger, denen mit konventionellen Impfstoffansätzen nicht beizukommen war. Zur Entwicklung dieser Impfstoffe trugen auch der Siegeszug der Gen- und Biotechnologie sowie die Etablierung neuer hocheffektiver Produktionsmethoden bei, die es ermöglicht haben, wie auch immer geartete Pathogene oder ihre spezifischen antigenen Strukturen in beliebigen Mengen sicher und großtechnisch herzustel- len. In diesem Zusammenhang müssen insbesondere auch die Fortschritte in den Zellkulturtechniken erwähnt werden, die es erlauben, veraltete Produktionsmethoden abzulösen, die häufig noch mit lebenden (!) Tieren, Tierembryonen oder Hühnereiern operierten. Inzwischen gibt es bereits zugelassene zellkulturabgeleitete Impfstoffe, die gegen Tollwut, Japanische Enzephalitis (eine weitere Flavivirus-Spezies) oder gegen Grippe gerichtet sind [28].

Der erste Impfstoff, der auf rekombinanter Gentechnologie und dem Einsatz von Zellkulturen beruhte, ist ein Impfstoff gegen das Hepatitis-B-Virus, der in den 1980er-Jahren registriert wurde. In diesem Fall konnten mittels genetischer Modifikationen nicht-infektiöse homologe Hepatitis-B-Virus-Partikel hergestellt werden, die dem Immunsystem bei Impfung die entscheidenden Antigene darbieten. Ein weiteres Paradebeispiel für einen rekombinanten Impfstoff ist der gegen $\mathrm{Hu}-$ mane Papillomaviren (HPV), die Genitalwarzen hervorrufen und Gebärmutterhalskrebs auslösen können [29]. Eine Variante solcher Impfstoffe nutzt heterologe Viruspartikel als Vektorsysteme für die schützenden Antigene des Erregers (zum Beispiel die ChimeriVax ${ }^{\mathrm{TM}}$-Impfstoffe).

Da nicht nur Eiweißkörper, sondern auch Zuckerstrukturen (Glykoside) antigene Eigenschaften besitzen, wurden auch diese für die Entwicklung von Impfstoffen verwendet. Ein Beispiel ist der Impfstoff für Erwachsene gegen die Pneumokokken. Bei ihm werden 23 Zuckerstrukturen verwendet [30]. Da isolierte Zuckerstrukturen oft nur unzureichend immu- 
nogen sind, hat man sie chemisch an Toxinproteine gekoppelt, die die Immunantwort dadurch verstärken, dass sie auch die zelluläre Immunantwort anstoßen. Beispiele hierfür sind die zugelassenen bakteriellen Kinderimpfstoffe gegen Haemophilus influenzae B und gegen Pneumokokken (das heißt, gegen die sieben prominentesten Serotypen von S. pneumoniae) [30]. Das Problem bei der Verwendung solcher Impfstoffe ist die hohe Varianz der Zuckerstrukturen innerhalb einer Erregerspezies. Zum Beispiel sind für S. pneumoniae weltweit mehr als 90 Serotypen isoliert worden, die sich durch ihre Oberflächenzucker unterscheiden.

Daher wurden Ansätze entwickelt, um in entzifferten Erregergenomen die bakteriellen Oberflächenproteine, das heißt die potenziellen Vakzinantigene, zu identifizieren, die zwischen allen klinisch relevanten Stämmen einer Spezies konserviert sind [31]. Die Wirksamkeit dieser Antigene muss natürlich zunächst in Tiermodellen validiert werden. Eine alternative Methode ist die Verwendung menschlicher Antikörper aus Individuen, die dem Erreger ausgesetzt waren und/oder die Krankheit erfolgreich überwunden haben, um mit ihrer Hilfe aus Proteinbibliotheken der Erreger geeignete Kandidatenantigene zu isolieren [32]. Impfstoffe, die derart definierte protektive Proteinantigene enthalten, sind derzeit in der Entwicklung beziehungsweise einige bereits in klinischen Zulassungsprüfungen. Beispiele sind Impfstoffe gegen nosokomiale Keime wie $S$. aureus und P. aeruginosa und Impfstoffe gegen Typ-B-Meningokokken und Pneumokokken [10, 33].

Genomische Ansätze zur Identifizierung schützender Antigene sind nicht auf Bakterienimpfstoffe beschränkt. Auf der Suche nach neuen und verbesserten $\mathrm{Vi}$ rusimpfstoffen werden bekannte oder neu entdeckte Antigene daraufhin analysiert, $\mathrm{ob}$ sie konservierte und immunogene $\mathrm{Ab}$ schnitte tragen, die alle Virusvarianten innerhalb einer Spezies abdecken. Im Bestreben, auch gegen Protozoen wie den Malariaerreger einen schützenden Impfstoff zu entwickeln, werden Antigene charakterisiert und getestet, die in einzelnen Lebensabschnitten des Erregers im Körper spezifisch exprimiert werden und für das Immunsystem am besten zugänglich sind. Es werden nicht nur Antigene gesucht und charakterisiert, die an Antikörper binden, sondern auch solche, die von T-Zellen erkannt werden, um zu gewährleisten, dass der Impfstoff eine breite Immunität induziert, die auch den T-ZellArm der Abwehr einschließt.

Nachteil des minimalistischen Impfansatzes ist, dass er nicht immer eine Immunantwort in der Breite und Tiefe anstößt, die für einen ausreichenden Schutz gegen einen Erreger erforderlich wäre. Bei Impfungen mit homologen oder auch heterologen lebenden, aber abgeschwächten Keimen ist die Chance besser, dass alle für den Aufbau der Abwehrkaskade benötigten Elemente des Immunsystems und der späteren adaptiven Immunantwort zum Tragen kommen. Daher wird an einer neuen Generation homologer sowie heterologer Lebendimpfstoffe gearbeitet, die durch genetische Modifikationen absolut ungefährlich werden. Auf der anderen Seite muss garantiert sein, dass diese Lebendimpfstoffe optimal mit dem Immunsystem interagieren, um eine schützende Immunität zu induzieren. Beispiel für einen entsprechenden viralen Lebendimpfstoff ist die neue RotavirusVakzine, die in der Pädiatrie zum Einsatz kommt [34]. Beispiel für einen bakteriellen Impfstoff ist ein neuer rekombinanter BCG-Impfstoff, bei dem Sicherheit und Immunstimulation verbessert sind [35]. Er befindet sich derzeit in der klinischen Prüfung.

Darüber hinaus werden zahlreiche neue Impfstoffe entwickelt, bei denen virale und bakterielle Vektorsysteme zum Einsatz kommen, die eine gegen heterologe Erreger schützende Immunität induzieren. An dieser Stelle sollte man kritisch anmerken, dass bei manchen Vektorsystemen (wie zum Beispiel bei chimären Flaviviren) ein gewisses Restrisiko der Bildung neuer Formen durch Rekombinationsereignisse nicht völlig ausgeschlossen werden kann [36].

Ein anderer Weg, um Untereinheitenimpfstoffe immunogener zu machen, ist der Einsatz von Adjuvanzien. Die Adjuvanzien, die bisher in registrierten Impfstoffen zur Anwendung kommen, beschränken sich auf Aluminiumsalze, auf das Liposom MF59 und auf Virosomen [37]. Eine neue Generation von Adjuvan- zien, die oft spezifische Schaltstellen des angeborenen Immunsystems ansteuern, ist derzeit in der Entwicklung. Ein neuer HPV-Impfstoff, der einen TLR-Agonisten enthält ist derzeit weltweit im Registrierungsprozess [38], weitere TLR-Agonisten sind in der klinischen Prüfung. Ein Beispiel ist $\mathrm{IC}_{31}{ }^{\oplus}$, das in einem neuen TB-Proteinimpfstoff klinische Prüfungen durchläuft. Neue Adjuvanzien, so vielversprechend ihre Profile auch aussehen mögen, werden von Zulassungsbehörden kritisch gesehen, denn ihre eindeutige Sicherheit und Nebenwirkungsfreiheit können sie schließlich erst in der Anwendung an einer großen Zahl von Menschen beweisen. Daher gibt es auf Behördenseite die Tendenz, der Anwendung eines neuen Adjuvans nur dann zuzustimmen, wenn der Impfstoff in der gegebenen Indikation nachweislich nur mithilfe des Adjuvans funktionieren kann.

Schließlich gibt es auch unterschiedliche Möglichkeiten, um Impfstoffe in den Körper einzubringen. Die meisten Impfstoffe, die heute verwendet werden, werden intramuskulär appliziert. Dieser Applikationsweg widerspricht eigentlich der immunologischen Erkenntnis, dass die Konzentration der APZ, die unmittelbar für den Aufbau einer Immunantwort verantwortlich sind, in der Oberhaut (Epidermis) am größten ist. Die historische Pockenimpfung hat dem Rechnung getragen und den Impfstoff in die Haut geritzt. In Studien - zum Beispiel mit therapeutischen Krebsimpfstoffen - wird der Impfstoff häufig in die Haut gespritzt, oft mit einer nachweislichen Verbesserung der erzielten Immunität. Da diese Applikation ärztliches Geschick erfordert und auch nicht ganz schmerzfrei ist, wurden neue Wege gesucht, um Impfstoffe direkt in die Epidermis zu applizieren. Ein neuer Grippeimpfstoff, der bei älteren und immununterdrückten Personen gute Wirkung zu zeigen scheint, wird zum Beispiel durch Mikronadeln direkt in die Epidermis appliziert [39]. Kürzlich wurde auch ein Impfstoff gegen den Durchfallerreger ETEC erfolgreich in einer klinischen Phase-II-Prüfung getestet [40]. Das Vakzin wird hier mithilfe eines Impfpflasters in die Epidermis eingebracht. Diese wird an der Anwendungsstelle so vorbereitet, dass vor Impfung eine einfache Entfer- 
nung der oberen Hornhautschicht möglich wird. Diese Ansätze können die Anwendung von Nadelapplikationen in $\mathrm{Zu}$ kunft deutlich reduzieren. Existierende Impfstoffe, zum Beispiel gegen Polio und Cholera, werden auch als Schluckimpfung verabreicht. Dabei wird die Immunität im Magen-Darm-Trakt aufgebaut, der ebenfalls sehr stark mit APZ durchsetzt ist. Bei allen neuen Impfungen ohne Nadel liegt allerdings die Herausforderung darin nachzuweisen, dass die Applikation zuverlässig ist. Eine kritische Frage ist in diesem Zusammenhang, welche Rolle die Applikationsstelle für die Art der induzierten Immunität spielt.

Ein weiterer minimalistischer, neuer Ansatz ist der Einsatz sogenannter DNAVakzine. Hier werden die Gene, die für die schützenden Antigene und die nötigen Hilfsproteine kodieren, in einen DNA-Vektor eingebracht und dieser als nackte, rekombinante DNA injiziert. An der Injektionsstelle wird die DNA von den Zellen aufgenommen, die entsprechenden Proteine werden dort exprimiert und dann vom Immunsystem erkannt. Die Methode hat im Tiermodell zu vielversprechenden Ergebnissen geführt, die Übertragung auf den Menschen hat sich aber aus technischen und regulatorischen Gründen als sehr schwierig erwiesen.

\section{Ausblick}

Der wissenschaftliche Fortschritt und die Technologiedurchbrüche der letzten drei Jahrzehnte haben die Entwicklung neuer, im letzten Jahrhundert noch undenkbarer Impfstoffe ermöglicht. Obwohl Impfstoffe zu den komplexesten Biologika gehören und ihre Entwicklung oft noch komplizierter ist als die gewöhnlicher Medikamente, hat sich ihr Einsatz nicht nur bewährt, sondern sie haben sich weltweit auch als nachhaltigste und kostengünstigste Säule der Gesundheitsversorgung erwiesen. Obwohl Impfstoffe nur zirka 5\% der Pharmaumsätze ausmachen, gehören sie zu dem am schnellsten wachsenden Segment der Branche mit einer Verdreifachung der Umsätze pro Jahrzehnt. Dem gegenüber stehen die Kostenersparnisse für das Gesundheitssystem, die im Multimilliardenbereich liegen. Die bisherigen Versuche, Infektionen global in den
Griff zu bekommen, wären hoffnungslos, gäbe es keine Impfstoffe. Ohne Vakzinierung und ihre Weiterentwicklung ist der Kampf gegen weltweite Seuchen nicht zu gewinnen. Neben häufigen und weniger häufigen „Killermikroben“ in den weniger entwickelten Ländern, die auch die entwickelte Welt bedrohen, gibt es eine stetig wachsende Zahl an neuen Infektionskrankheiten, die vor keinen Grenzen haltmachen [41]. Darüber hinaus ist die Euphorie der Penizillinentdeckung vor zirka 70 Jahren inzwischen der Ernüchterung gewichen, dass vielen Infektionskrankheiten nicht mehr hinreichend mit Antibiotika begegnet werden kann, sodass selbst chirurgische Routineeingriffe oder krankheitsbedingte Schwächen aufgrund von Infektionen häufiger zum Tod führen, als wir das gerne zugeben.

Da eine nicht unerhebliche Zahl von schweren, oft unheilbaren Krankheiten wie spezifische Krebsarten, Autoimmunkrankheiten und neuropathologische $\mathrm{Zu}$ stände mit chronischen Mikrobeninfektionen in Verbindung gebracht werden, besteht die Hoffnung, dass vorbeugende Impfungen und Behandlungen gegen solche Erreger die Inzidenzen dieser Erkrankungen verringern könnten. Die Einführung der HBV- und der HPV-Vakzine gibt Anlass zur Hoffnung, dass die Inzidenzen der entsprechenden Krebsformen bald deutlich abnehmen werden.

Die enormen Fortschritte in der Immunologie, gepaart mit den Entwicklungen in den Vakzintechnologien, haben den Weg für neue Impfstofftypen geebnet. Ein Beispiel sind therapeutische Impfstoffe, die in der Onkologie mit teils vielversprechenden Einzelergebnissen, aber bisher ohne Durchbruch bei der Zulassung, getestet werden. Therapeutische Impfungen gegen chronische HCV- und HPV-Infektionen zeigen erste Resultate, die man als „Proof of Principle“ interpretieren kann [42]. Weitere Zielkrankheiten für therapeutische Impfstoffe sind Allergien, Nikotinabhängigkeit und neurodegenerative Krankheiten wie Morbus Alzheimer [43]. Darüber hinaus erlauben die verfeinerten molekularbiologischen Werkzeuge, hochspezifische Impfantigene zu identifizieren. Auch die Revitalisierung eines klassischen Paradigmas, das schon vor Entdeckung der Antibiotika Eingang in die Medizin gefunden hatte, hat heute wieder an Bedeutung gewonnen: der vorbeugende Einsatz und die Behandlung mit antiinfektiven Antikörpern. Antikörper, in Form spezifischer tierischer Antiseren, wurden historisch oft mit Erfolg eingesetzt, um bakterielle Infektionen zu bekämpfen. Der rasante Fortschritt bei den neuen Antikörpertechnologien, die es erlauben, kostengünstig beliebige Mengen hochspezifischer Antikörper herzustellen, und die schnellen diagnostischen Methoden, die es ermöglichen, Erreger direkt am Krankenbett zu bestimmen, könnten die Basis bilden, um Antikörper in kritischen Hospitalsituationen, zum Beispiel auf Intensivstationen, als letzte Möglichkeit einzusetzen.

\section{Korrespondenzadresse \\ Prof. Dr. Dr. h.c. S.H.E. Kaufmann \\ Max-Planck-Institut \\ für Infektionsbiologie \\ Charitéplatz 1, \\ 10117 Berlin \\ kaufmann@mpiib-berlin.mpg.de}

Danksagung. Wir danken Frau S. Sibaei und Frau M. Grafl für ihre wertvolle Hilfe bei der Erstellung des Manuskripts.

Interessenkonflikt. Der korrespondierende Autor weist auf folgende Beziehungen hin:

S.H.E. Kaufmann ist Ko-Erfinder eines rekombinanten BCG-Stamms gegen TB, der derzeit von der Vakzine Projekt Management $\mathrm{GmbH}$ in klinischen Studien getestet wird. Er ist weiterhin Mitglied des Wissenschaftlichen Beirats der Vakzine Projekt Management $\mathrm{GmbH}$ und von Intercell AG, die er in dieser Funktion auch in Fragen zur Impfstoffentwicklung gegen Krankheitserreger berät.

A.L. Meinke ist Angestellter der Intercell AG, einer Biotechnologiefirma in Wien, Österreich. Zudem ist er Ko-Autor von mehreren Patenten für zahlreiche Proteinantigene, von denen einige (S.-aureus- und S.-pneumoniae-Impfstoffe) derzeit in klinischen Prüfungen evaluiert werden.

A. von Gabain ist Vorstand und Mitbegründer der Intercell AG, einer Biotechnologiefirma in Wien, Österreich. Zudem ist er Ko-Autor von mehreren Patenten, von denen einige derzeit in klinischen Prüfungen evaluiert werden.

\section{Literatur}

1. Roush SW, Murphy TV, Vaccine-Preventable Disease Table Working Group (2007) Historical comparisons of morbidity and mortality for vaccinepreventable diseases in the United States. JAMA 298:2155-2163 
2. Roberts $L$ (2009) Polio eradication. Looking for a little luck. Science 323:702-705

3. Breman JG, Arita I (1980) The confirmation and maintenance of smallpox eradication. $\mathrm{N}$ Engl J Med 303:1263-1273

4. Kim WM, Sigalov AB (2008) Viral pathogenesis, modulation of immune receptor signaling and treatment. Adv Exp Med Biol 640:325-349

5. Walker BD, Burton DR (2008) Toward an AIDS vaccine. Science 320:760-764

6. Fedtke I, Götz F, Peschel A (2004) Bacterial evasion of innate host defenses - the Staphylococcus aureus lesson. Int J Med Microbiol 294:189-194

7. Kwinn LA, Nizet V (2007) How group A Streptococcus circumvents host phagocyte defenses. Future Microbiol 2:75-84

8. Kaplan MH, Meyeserian M (1962) An immunological cross-reaction between group-A streptococcal cells and human heart tissue. Lancet 1:706-710

9. Sievert DM, Rudrik JT, Patel JB et al (2008) Vancomycin-resistant Staphylococcus aureus in the United States, 2002-2006. Clin Infect Dis 46:668-674

10. Kuklin NA, Clark DJ, Secore S et al (2006) A novel Staphylococcus aureus vaccine: iron surface determinant $B$ induces rapid antibody responses in rhesus macaques and specific increased survival in a murine $S$. aureus sepsis model. Infect Immun 74:2215-2223

11. Werner G, Coque TM, Hammerum AM et al (2008) Emergence and spread of vancomycin resistance among enterococci in Europe. Euro Surveill 13:19046

12. Gould CV, McDonald LC (2008) Bench-to-bedside review: Clostridium difficile colitis. Crit Care 12:203

13. Vonberg RP, Kuijper EJ, Wilcox MH et al (2008) Infection control measures to limit the spread of Clostridium difficile. Clin Microbiol Infect 14 (Suppl 5):2-20

14. Lim PL, Barkham TM, Ling LM et al (2008) Increasing incidence of Clostridium difficile-associated disease, Singapore. Emerg Infect Dis 14:14871489

15. Rosenthal VD, Maki DG, Mehta A, International Nosocomial Infection Control Consortium Members et al (2008) International Nosocomial Infection Control Consortium report, data summary for 2002-2007. Am J Infect Control 36:627-637

16. Fauci AS, Johnston MI, Dieffenbach CW et al (2008) HIV vaccine research: the way forward. Science 321:530-532

17. Thimme R, Neumann-Haefelin C, Boettler T, Blum HE (2008) Adaptive immune responses to hepatitis $C$ virus: from viral immunobiology to a vaccine. Biol Chem 389:457-467

18. ter Meulen J (2007) Monoclonal antibodies for prophylaxis and therapy of infectious diseases. Expert Opin Emerg Drugs 12:525-540

19. Nagy E, Giefing C, von Gabain A (2008) Anti-infective antibodies: a novel tool to prevent and treat nosocomial diseases. Expert Rev Anti Infect Ther 6:21-30

20. Mansouri E, Blome-Eberwein S, Gabelsberger J et al (2003) Clinical study to assess the immunogenicity and safety of a recombinant Pseudomonas aeruginosa OprF-Oprl vaccine in burn patients. FEMS Immunol Med Microbiol 37:161-166

21. Kaufmann SHE (2008) Immunologie. In: Hahn $\mathrm{H}_{\text {, }}$ Kaufmann SHE, Schulz TF, Suerbaum S (Hrsg) Medizinische Mikrobiologie und Infektiologie, 6 . Ausgabe. Springer, Berlin Heidelberg, S 37-117

22. Kaufmann SHE (2007) The contribution of immunology to the rational design of novel antibacterial vaccines. Nat Rev Microbiol 5:491-504
23. Kaufmann SHE, Parida S (2008) Tuberculosis in Africa: learning from pathogenesis for biomarker identification. Cell Host Microbe 4:219-228

24. Plotkin SA (1999) Vaccination against the major infectious diseases. C R Acad Sci III 322:943-951

25. Richards AL (2004) Rickettsial vaccines: the old and the new. Expert Rev Vaccines 3:541-555

26. Plotkin SA (2005) Vaccines: past, present and future. Nat Med 11:S5-S11

27. O'Hagan DT (2007) MF59 is a safe and potent vaccine adjuvant that enhances protection against influenza virus infection. Expert Rev Vaccines 6:699 710

28. Tsiang $H$ (1998) Rabies vaccines: a review of progress towards improved efficacy and safety. BioDrugs 10:317-328

29. Shi L, Sings HL, Bryan JT et al (2007) GARDASIL: prophylactic human papillomavirus vaccine development - from bench top to bed-side. Clin Pharmacol Ther 81:259-264

30. Mulholland K (1999) Strategies for the control of pneumococcal diseases. Vaccine 17:S79-S84

31. Mora M, Donati C, Medini D et al (2006) Microbial genomes and vaccine design: refinements to the classical reverse vaccinology approach. Curr Opin Microbiol 9:532-536

32. Meinke A, Henics T, Hanner M et al (2005) Antigenome technology: a novel approach for the selection of bacterial vaccine candidate antigens. Vaccine 23:2035-2041

33. Giefing C, Meinke A, Hanner M et al (2008) Discovery of a novel class of highly conserved vaccine antigens using genomic scale antigenic fingerprinting of Pneumococcus with human antibodies. J Exp Med 205:117-131

34. Dennehy PH (2008) Rotavirus vaccines: an overview. Clin Microbiol Rev 21:198-208

35. Grode L, Seiler P, Baumann S et al (2005) Increased vaccine efficacy against tuberculosis of recombinant Mycobacterium bovis bacille Calmette-Guérin mutants that secrete listeriolysin. J Clin Invest 115:2472-2479

36. Seligman SJ, Gould EA (2004) Live flavivirus vaccines: reasons for caution. Lancet 363:2073-2075

37. Lingnau K, Riedl K, von Gabain A (2007) IC31 and IC30, novel types of vaccine adjuvant based on peptide delivery systems. Expert Rev Vaccines 6:741-746

38. Descamps D, Hardt K, Spiessens B et al (2009) Safety of human papillomavirus (HPV)-16/18 AS04adjuvanted vaccine for cervical cancer prevention: a pooled analysis of 11 clinical trials. Hum Vaccin 5:332-340

39. Holland D, Booy R, De Looze F et al (2008) Intradermal influenza vaccine administered using a new microinjection system produces superior immunogenicity in elderly adults: a randomized controlled trial. J Infect Dis 198:650-658

40. Frech SA, Dupont HL, Bourgeois AL et al (2008) Use of a patch containing heat-labile toxin from Escherichia coli against travellers' diarrhoea: a phase II, randomised, double-blind, placebo-controlled field trial. Lancet 371:2019-2025

41. Kaufmann SHE (2007) Wächst die Seuchengefahr? In: Wiegand K (Hrsg) Globale Epidemien und Armut: Strategien zur Seucheneindämmung in einer vernetzten Welt. Fischer Taschenbuchverlag, Frankfurt

42. Klade CS, Wedemeyer $H$, Berg T et al (2008) Therapeutic vaccination of chronic hepatitis $C$ nonresponder patients with the peptide vaccine IC41. Gastroenterology 134:1385-1395
43. Schneeberger A, Mandler M, Otawa O et al (2009) Development of Affitope Vaccines for Alzheimer's Disease (AD) - from concept to clinical testing. J Nutr Health Aging 13:264-267

44. World Health Organization (2008) The global burden of disease: 2004 update. ISBN 978924156371 0 (NLM classification: W 74) @ World Health Organization 